\title{
Slab pull, slab weakening, and their relation to deep intra-slab seismicity
}

\author{
Susan L. Bilek \\ Earth and Environmental Science Department, New Mexico Institute of Mining and Technology, Socorro, \\ New Mexico, USA \\ Clinton P. Conrad and Carolina Lithgow-Bertelloni \\ Department of Geological Sciences, University of Michigan, Ann Arbor, Michigan, USA
}

Received 8 March 2005; revised 3 June 2005; accepted 21 June 2005; published 21 July 2005.

[1] Subduction zone seismicity is highly variable. Great earthquakes occur at few subduction zones around the world, with significant variation in size and frequency of deep events. Interactions between overriding and subducting plates and slab pull strength for individual plates provide a framework for understanding these variations. Previous work suggests an inverse correlation between great earthquake moment release and the degree to which the subducted slab is connected to the surface plate. We find positive correlations between degree of plate-slab attachment and moment release from intermediate and deep earthquakes. This implies that shallow slab weakening that occurs at trenches where compressive stresses (and great earthquakes) dominate not only detaches slabs from plates, but is maintained as the slab descends, discouraging deep seismicity. Regions of low shallow moment release are consistent with extensional shallow stress regimes and undamaged slabs. Such slabs maintain mechanical strength during descent and deform seismogenically at depth. Citation: Bilek, S. L., C. P. Conrad, and C. LithgowBertelloni (2005), Slab pull, slab weakening, and their relation to deep intra-slab seismicity, Geophys. Res. Lett., 32, L14305, doi:10.1029/2005GL022922.

\section{Introduction}

[2] Subduction zones produce a significant portion of global seismicity and generate subducted slabs, which are the most important energy source for plate driving forces [e.g., Conrad and Lithgow-Bertelloni, 2002]. The occurrence of great earthquakes $\left(\mathrm{M}_{\mathrm{w}}>8.2\right)$ can be linked to the state of stress in the back-arc [Uyeda and Kanamori, 1979], the age of the lithosphere and its rate of convergence [Ruff and Kanamori, 1980], all factors which may be directly related to plate driving forces [Conrad et al., 2004]. The frequency and magnitude of intermediate $(\sim 100-300 \mathrm{~km})$ and deep $(>300 \mathrm{~km})$ intraslab earthquakes also varies. The exact physical mechanism that controls deep focus seismicity is a source of ongoing debate [Green and Zhou, 1996; Silver et al., 1995]. If intermediate and deep seismicity is caused by the reactivation of preexisting faults in the oceanic lithosphere [Silver et al., 1995; Jiao et al., 2000], slabs must maintain a degree of "elastic" strength. This mechanical strength is

Copyright 2005 by the American Geophysical Union. 0094-8276/05/2005GL022922 the basis for the slab pull force, in which the excess weight of a slab is transmitted to the surface plate by guiding stresses within the slab [Christova and Scholz, 2003; Conrad et al., 2004]. Hence we might expect a relationship between slabs that are able to transfer stress effectively to the surface (i.e. having strong plate-slab attachment) and the frequency and magnitude of intermediate and deep focus earthquakes.

[3] The degree of attachment between subducting plates and slabs may vary between subduction zones if the mechanical strength of slabs varies. Because the pull force from upper mantle slabs is essential for driving plates at the right speeds and directions [Conrad and LithgowBertelloni, 2002], variations in strength may significantly affect plate motions [Conrad et al., 2004]. By comparing predicted and observed plate motions, Conrad et al. [2004] inverted for the degree of attachment between subducting plates and the upper mantle slabs that pull them ("pull fraction") that must operate at each subduction zone to yield the best fit to observed plate motions. They found that some slabs must be strongly attached to their surface plates (such as Tonga (TON) and Marianas-Izu Bonin (MIZ)) while other slabs must be detached (such as Alaska (ALT) and Japan-Kamchatka (JKK)) (Figure 1).

[4] Because slab weakening may also be associated with slab deformation, these variations between subduction zones suggest possible variations in seismicity. Using a dataset of great earthquakes from Ruff and Kanamori [1980], Conrad et al. [2004] found seismic moment release from subduction zones with strong plate-slab attachment to be significantly smaller than those with lower plate-slab attachment. For example, CHL and ALT both experienced great earthquakes, 1960 Chile and 1964 Alaska, and both have relatively low plate-slab attachment $(40 \%$ for CHL, $0 \%$ for ALT), whereas zones with few to no great earthquakes (TON and MIZ) occur at strongly attached slabs (nearly $100 \%$ coupled). The occurrence of great earthquakes has been linked with compressional tectonic environments that exhibit back-arc compression and overriding plate motion towards the trench [e.g., Ruff and Kanamori, 1980]. Conrad et al. [2004] show that these zones also transmit a weak slab pull force, possibly resulting from a damaged or weakened slab. This weakening can be caused by the dominant compressive stresses near the surface in these regions. For regions of back-arc extension without great earthquakes, no slab weakening occurs and strong plate-slab attachment allows for stress transmission within the slab. 


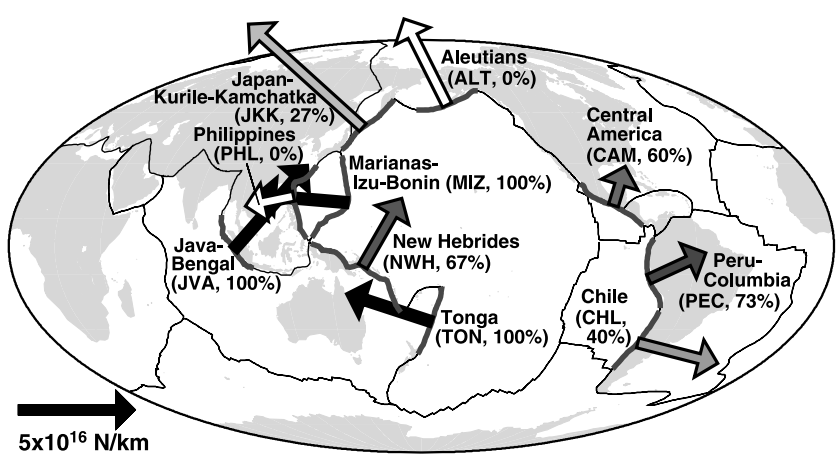

Figure 1. The magnitude and direction of the maximum possible slab pull force (arrows), determined as the excess weight of subducted material in the upper mantle, for the 10 different subduction zones defined by Conrad et al. [2004]. Subduction zones are noted in later figures by the abbreviations shown here. The saturation of shading in the interior of each arrow, as well as percentages given by their labels, denotes the fraction of the maximum pull force, that when applied as a force on the subducting plate, provides the best fit to observed plate motions.

[5] These results suggest that surface stress conditions weaken some slabs as they subduct, breaking their attachments to their surface plates or their ability to transmit stress effectively to the surface. If these slabs remain weak as they descend, they may produce fewer earthquakes of smaller magnitudes as they descend within the upper mantle. On the other hand, zones with strong plate-slab attachment that do not experience slab weakening near the surface should retain their mechanical strength and produce earthquakes at depth. In this paper, we examine relationships between the degree of plate-slab attachment, as described by relative fractions of slab pull force, and patterns of earthquake depths, focal mechanisms, and down-dip stresses throughout the upper mantle slab.

\section{Earthquake Catalog and Selection Criteria}

[6] Earthquakes were selected from the Harvard Centroid Moment Tensor Catalog (Dziewonski et al. [1981] and later updates). The Harvard CMT catalog provides location, depth and focal mechanism information routinely for earthquakes with moment magnitude $\left(\mathrm{M}_{\mathrm{w}}\right)$ greater than 5.5 since 1977. The primary criterion for selecting earthquakes was hypocentral location relative to the subduction zone of interest. This subduction zone dataset, also used by Conrad et al. [2004], includes 10,993 earthquakes (from 1977-mid2002) occurring at the interface between the subducting and overriding plate as well as earthquakes occurring within the subducting slab. We examined earthquake hypocenters at each subduction zone to remove events occurring in the outer rise as well as earthquakes occurring within the upper plate.

[7] Because the earthquake dataset ends in June 2002, it does not include the great earthquakes that have occurred since 2002, most significantly the $2004 \mathrm{M}_{\mathrm{w}} 9.0$ earthquake in Sumatra (JVA grouping). Estimates of moment release from this earthquake will shift the JVA point at shallow depth and reduce the correlation of Conrad et al. [2004].
However, preliminary modeling suggests the need for revised plate geometries to include the Indian and Sunda plates, and subsequent re-estimation of the pull force for the northern JVA slab. As this paper focuses largely on intermediate and deep earthquakes, the shallow 2004 earthquake has little effect on these results.

[8] Harvard CMT catalog parameters are further used to classify earthquakes by depth and mechanism. We use the catalog centroid depth for depth classification. For shallow earthquakes, focal mechanisms are based on the pressure, tension, and null (P, T, B) axes for each earthquake. Thrust mechanism earthquakes are classified based on a large plunge $\left(>45^{\circ}\right)$ of the $\mathrm{T}$ axis. Normal fault mechanism earthquakes have small plunge $\left(<45^{\circ}\right)$ of the $\mathrm{T}$ and $\mathrm{B}$ axes, and strike slip events have a large $\left(>45^{\circ}\right)$ plunge of the B axis. We follow Isacks and Molnar [1971] to classify intermediate $(100-300 \mathrm{~km})$ and deep $(>300 \mathrm{~km})$ earthquakes, defining downdip compression for earthquakes that have $\mathrm{P}$ axes within $20^{\circ}$ of the slab dip and downdip extension where the $\mathrm{T}$ axis is within $20^{\circ}$ of the slab dip. Slab dip for intermediate and deep depth ranges are estimated from the subduction zone grouping of Jarrard [1986] using the deep slab $(>100 \mathrm{~km})$ category, averaged over the length of each subduction zone segment.

\section{Relationships Between Slab Pull Fraction and Earthquake Parameters}

[9] The relationship between shallow ( $<100 \mathrm{~km}$ depth) moment release and pull fraction suggests a weak inverse correlation (Figure 2). Conrad et al. [2004] found similar behavior using both the Harvard and Ruff and Kanamori [1980] catalogs, which are substantially different, and implies that the correlation we observe is not controlled by the completeness of the catalog. Indeed, the two catalogs

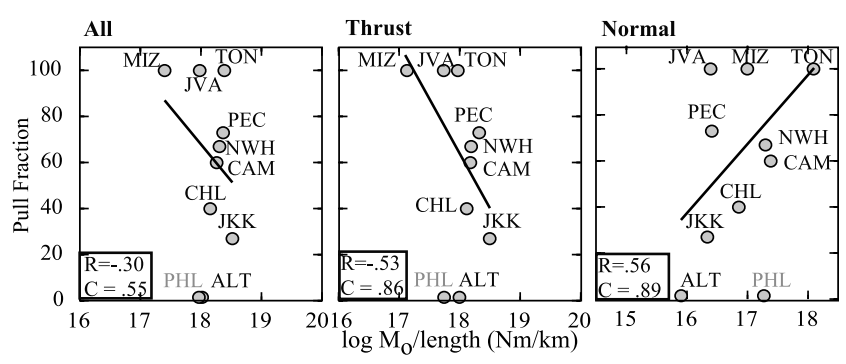

Figure 2. Comparisons of best-fit pull fraction and shallow earthquake (depth $0-100 \mathrm{~km}$ ) moment release scaled by length of subduction zone. First panel shows log of moment release in all earthquakes within this depth range, and remaining panels are separated by mechanism. The lines drawn are the least-squares best fit to the set of subduction zones in black. Pearson's correlation coefficient (R) and 2-sided confidence level (C) are shown to indicate that the correlations are not random [Press et al., 1997]. PHL subduction zone (shaded) inversion results are poorly constrained and are not used to compute the best fit or $\mathrm{R}$ values [Conrad et al., 2004]. Note the inverse correlation between moment release and pull fraction (all) is dominated by the thrust mechanism earthquakes. Normal events produce less moment, but have positive correlation with pull fraction. 


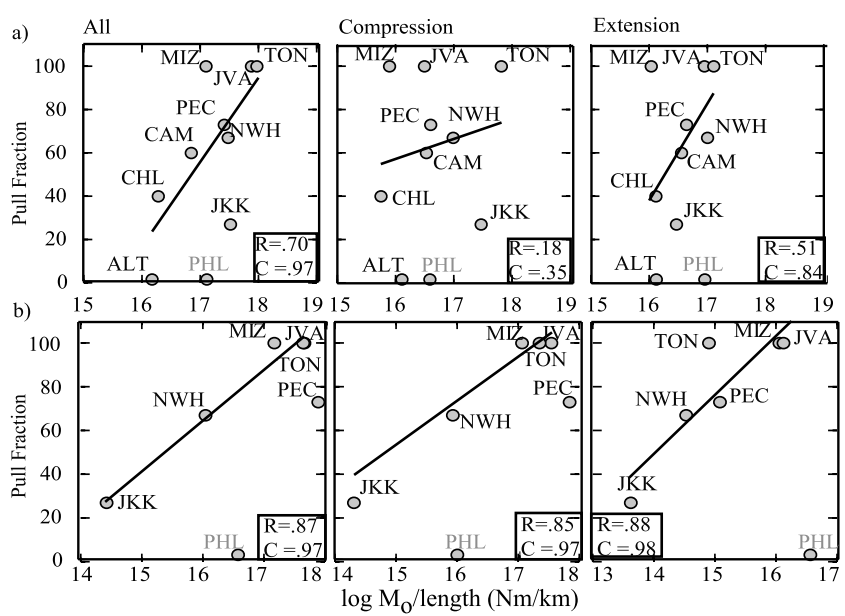

Figure 3. Best-fit pull fraction compared to (a) intermediate depth earthquake moment release and (b) deep earthquake moment release scaled by length of subduction zone. First panel indicates moment release in all earthquakes within this depth range, second panel shows moment release for earthquakes with $\mathrm{P}$ axis suggesting downdip compression, third panel shows moment release with $\mathrm{T}$ axis suggesting downdip extension. The least squares fit and $\mathrm{R}$ value are given in Figure 2. In Figure 3a, intermediate depth earthquakes between $100-300 \mathrm{~km}$ show a significant positive correlation between pull fraction and moment release in the total dataset as well as in dataset of earthquakes indicating downdip extension. In Figure 3b, deep earthquakes show a similar positive correlation between moment release and pull fraction.

differ by the time-frame spanned and by earthquakes included; Ruff and Kanamori [1980] includes only the largest interface earthquake per subduction zone in the 20 th century. Grouping moment release by mechanism (Figure 2) shows the dominance of thrust mechanism events in this depth range, with the inverse correlation for thrust events similar to the cumulative moment release. Zones with high pull fraction have more normal faulting moment release than regions with smaller pull fraction, which supports the notion that a more extensional subduction environment allows for a more coherent shallow slab that can effectively transmit the slab pull force.

[10] Cumulative moment release for intermediate depth earthquakes shows large moment release for subduction zones with high pull fraction, opposite that seen for the shallow events (Figure 3a). Much of the positive correlation is driven by downdip extensional earthquakes. There is no clear correlation between pull fraction and moment release for downdip compressional events in this depth range, despite significant moment release by these earthquakes. Previous studies of intermediate depth earthquakes suggest significant scatter in the $\mathrm{P}$ and $\mathrm{T}$ axes, but there is a slight tendency towards more events indicating downdip tension [e.g., Spence, 1987; Vassiliou and Hager, 1988; Chen et al., 2004]. There may also be depth variations in levels of downdip tension in this range, as suggested by Christova and Scholz [2003] for intermediate depth earthquakes occurring in portions of the New Hebrides subduction zone.
[11] Deep earthquakes show the strongest positive correlation between pull fraction and moment release (Figure 3b). Several of the subduction zones do not have any deep earthquakes in this catalog, such as ALT, CHL, and CAM, and are thus excluded from these panels, as expected if our hypothesis is correct. The majority of moment release occurs in earthquakes with mechanisms suggestive of downdip compression, consistent with previous studies [Isacks and Molnar, 1971; Vassiliou and Hager, 1988; Jiao et al., 2000]. Earthquakes with downdip extensional mechanisms also exhibit a strong positive correlation with pull fraction, but there is significantly less moment released by these earthquakes.

[12] To further examine the possible errors associated with catalog completeness, we also compare pull fraction with moment release from a subset of earthquakes with $\mathrm{M}_{\mathrm{w}}=6-7$. The $\mathrm{R}$ values are 0.31 and 0.84 for intermediate and deep events, respectively. The similarity with the positive correlations for all events suggests that this is truly a variation in the ability of some slabs to generate seismicity and not just differences in occurrence of the largest earthquakes, which dominate cumulative moment release.

[13] Earthquake occurrence also varies with the degree of plate-slab attachment (Figure 4). Levels of intermediate depth seismicity show a weak trend towards higher numbers of earthquakes in regions of greater pull (>70\%). Roughly an equal number of earthquakes occur for both downdip compression and extension, suggesting significant variability of focal mechanisms. Deep earthquakes preferentially occur in regions of high pull fraction. Here the majority of earthquakes indicate downdip compression, although TON has a significant number of earthquakes with $\mathrm{T}$ axes indicative of downdip extension. This may be related to along strike variations within the large extent of our TON zone, as Chen et al. [2004] observed a change from clear downdip compression in the northern portion of the region towards downdip tension to the south.

\section{Discussion}

[14] Our results can be examined in the context of the model proposed by Conrad et al. [2004]. In this model, great

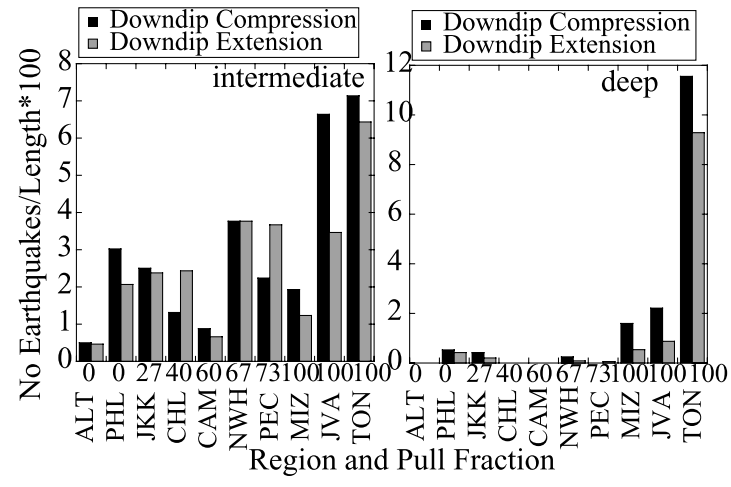

Figure 4. Number of earthquakes in each zone, scaled by length of subduction zone, as a function of pull fraction. Colors indicate downdip compression/extension for intermediate and deep earthquakes. More earthquakes occur in zones with higher plate-slab coupling (pull fraction). 
shallow thrust earthquakes occur in subduction zones with small levels of slab pull. Shallow compressional behavior in regions where the overriding plate strongly overrides the trench, causes weakening of the slab that prevents the transmission of significant pull to the surface plate. At intermediate and deep depths, we observe diminished levels of seismicity and moment release for these subduction zones. It appears that a slab that becomes weakened or damaged by compressional forces at shallow depths retains these characteristics as it descends. Because their elastic strength has been diminished by increased deformation and seismicity at shallow depths, these slabs (ALT, CHL, JKK) are not coherent enough at depth to generate significant seismicity when undergoing deformation.

[15] Conversely, in regions with no great earthquakes and lower overall moment release for shallow earthquakes, Conrad et al. [2004] found strong plate-slab attachment. For these subduction zones (MIZ, TON, JVA), the overriding plate motion is typically away from the trench, and thus does not exert compressional stresses on the slab that tend to weaken it. The extensional subduction environment allows these slabs to maintain enough strength to transmit pull forces as they descend through the upper mantle. Because they maintain elastic coherency as they descend, these slabs will respond to external forces by deforming seismogenically, in agreement with our observations of increased moment release and numbers of earthquakes for intermediate and deep focus earthquakes in these subduction zones.

[16] Other studies of intermediate and deep earthquakes also suggest variability between subduction zones. Wiens [2001] finds that thermal properties of the slabs correlate with earthquake b-values and aftershock production of deep earthquakes, with colder slabs (higher thermal parameter) yielding higher b-values and more aftershocks than warmer slabs. We do not see a clear relationship in our dataset with their defined thermal parameter. Zones like TON, MIZ, and JVA have large moment release by deep earthquakes, high plate-slab attachment, and are cold (high thermal parameter). However, PEC and CHL, assigned a low thermal parameter, have intermediate levels of seismicity and plate-slab attachment. Thus it does not appear that our defined plate-slab attachment parameter is simply related to the thermal differences. Instead, such differences are more likely related to slab weakness or damage introduced by compressive stresses in the shallow subduction region.

[17] Our results have important implications for slab and mantle rheology. The compressional interaction of slabs and overriding plates may weaken slabs through either the stress-dependence associated with power-law dislocation creep [e.g., Kohlstedt et al., 1995], or via several strain-rate dependent mechanisms such as viscous heating coupled with temperature-dependence or volatile (e.g. water) ingestion into microcracks in deforming rocks [Bercovici, 1996, 1998]. While all these mechanisms provide a weak slab at shallow depths (where dislocation creep applies), only strain-weakening causes the slab to remain weak as it descends into the mantle, where diffusion creep is favored. Although recent studies suggest that dislocation creep persists at high pressure [Mainprice et al., 2005], the near-surface deviatoric stresses imposed by compressional interaction of the slab and overriding plate diminish as the slab descends, allowing the slab to restrengthen. By contrast, both strain-rate dependent mechanisms likely cause a permanent weakening of the slab as the added heat or volatiles would be retained as the slab descends. Unlike stress-dependent rheologies, strain-rate dependent mechanisms produce self-lubricating plate boundaries in models of mantle convection with self-generating plates [Bercovici, 1996, 1998]. Our results suggest that strain-rate dependent rheology may be responsible for permanently weakening some slabs.

\section{Conclusions}

[18] We compare our compilation of subduction zone moment release with estimates of slab pull acting on individual subducting slabs. We find that shallow moment release is greater at subduction zones in which slabs are poorly attached to subducting plates, which is expected if compressional stresses weaken the slab and generate seismicity. These slabs remain weak as they descend, producing little seismicity in the 100-300 and 300-670 km depth ranges, as expected for viscous heating or void-volatile weakening. Conversely, slabs that are well attached to subducting plates maintain their mechanical strength as they descend through the shallow subduction zone. These slabs instead remain seismogenic as they descend through the upper mantle.

[19] Acknowledgments. We would like to thank 2 anonymous reviewers for their constructive comments. Partial support for this research provided by Alfred P. Sloan Foundation and NSF-EAR-9980551 (CLB).

\section{References}

Bercovici, D. (1996), Plate generation in a simple model of lithosphericmantle flow with dynamic self-lubrication, Earth Planet. Sci. Lett., 144, 41-51.

Bercovici, D. (1998), Generation of plate tectonics from lithospheric-mantle flow and void-volatile self-lubrication, Earth Planet. Sci. Lett., 154, $129-151$

Chen, P.-F., et al. (2004), A global survey of stress orientations in subducting slabs as revealed by intermediate depth earthquakes, Geophys. J. Int., $159,721-733$.

Christova, C., and C. H. Scholz (2003), Stresses in the Vanuatu subducting slab: A test of two hypotheses, Geophys. Res. Lett., 30(15), 1790, doi:10.1029/2003GL017701.

Conrad, C. P., and C. Lithgow-Bertelloni (2002), How mantle slabs drive plate tectonics, Science, 298, 207-209.

Conrad, C. P., et al. (2004), Great earthquakes and slab-pull: Interaction between seismic coupling and plate-slab coupling, Earth Planet. Sci. Lett., 218, 109-122.

Dziewonski, A. M., T.-A. Chou, and J. H. Woodhouse (1981), Determination of earthquake source parameters from waveform data for studies of global and regional seismicity, J. Geophys. Res., 86, 2825-2852.

Green, H. W., II, and Y. Zhou (1996), Transformation-induced faulting requires an exothermic reactions and explains the cessation of earthquakes at the base of the mantle transition zone, Tectonophysics, 256, $39-56$.

Isacks, B. L., and P. Molnar (1971), Distribution of stresses in the descending lithosphere from a global survey of focal mechanism solutions of mantle earthquakes, Rev. Geophys., 9, 103-174.

Jarrard, R. D. (1986), Relations among subduction parameters, Rev. Geophys., 24, 217-284.

Jiao, W., P. G. Silver, Y. Fei, and C. T. Prewitt (2000), Do intermediate and deep-focus earthquakes occur on pre-existing weak zones? An examination of the Tonga subduction zone, J. Geophys. Res., 105, 28,12528,138 .

Kohlstedt, D. L., B. Evans, and S. J. Mackwell (1995), Strength of the lithosphere: Constraints imposed by laboratory experiments, J. Geophys. Res., 100, 17,587-17,602. 
Mainprice, D., et al. (2005), Pressure sensitivity of olivine slip systems and seismic anisotropy of Earth's upper mantle, Nature, 433, 731-733.

Press, W. H., et al. (1997), Numerical Recipes in C, 2nd ed., 994 pp., Cambridge Univ. Press, New York.

Ruff, L. J., and H. Kanamori (1980), Seismicity and the subduction process, Phys. Earth Planet. Inter, 23, 240-252.

Silver, P. G., et al. (1995), Rupture characteristics of the deep Bolivian earthquake of 9 June 1994 and the mechanism of deep focus earthquakes, Science, 268, 69-73.

Spence, W. (1987), Slab pull and the seismotectonics of subduction lithosphere, Rev. Geophys., 25, 55-69.

Uyeda, S., and H. Kanamori (1979), Back-arc opening and the mode of subduction, J. Geophys. Res., 84, 1049-1061.
Vassiliou, M. S., and B. H. Hager (1988), Subduction zone earthquakes and stress in slabs, Pure Appl. Geophys., 128, 547-624.

Wiens, D. A. (2001), Seismological constraints on the mechanism of deep earthquakes: Temperature dependence of deep earthquake source properties, Phys. Earth. Planet. Inter., 127, 145-163.

S. L. Bilek, Earth and Environmental Science Department, New Mexico Institute of Mining and Technology, 801 Leroy Drive, Socorro, NM 87801, USA. (sbilek@nmt.edu)

C. P. Conrad and C. Lithgow-Bertelloni, Department of Geological Sciences, University of Michigan, Ann Arbor, MI 48109, USA. 